\title{
An evaluation of a Housing First program for chronically homeless women
}

\author{
Abe Oudshoorn \\ Western University \\ Cheryl Forchuk \\ Western University \\ Jodi Hall \\ Western University \\ Tracy Smith-Carrier \\ Western University \\ Amy Van Berkum \\ St. Josephs Health Care London
}

\section{Abstract}

Housing First is rapidly developing as a promising practice for ending homelessness. However, concerns have been raised regarding application for particular populations, such as women. Using a critical feminist lens, this evaluation assessed a Housing First program delivered in a mid-sized city in Ontario, Canada. The evaluation included interviews with program participants, program providers, and community key informants. Ultimately, the program proved successful in housing a small group of chronically homeless women, demonstrating that Housing First works with women, and works best when designed with the unique needs of women taken into consideration. The program achieved moderate fidelity to the Housing First model, and a number of recommendations are provided to better meet the unique needs of women. In particular, the issue of unresolved grief and loss in the context of child apprehension was identified as a root cause of ongoing trauma. Consideration is also given to the intersection between mental health services and Housing First programs.

Keywords: Housing First, homelessness, gender, women, housing, trauma

\section{Introduction}

The experience of homelessness is considered to be very much a gendered experience (Berman et al., 2011). For women and girls, violence and trauma are over-arching themes,

Corresponding author: Abe Oudshoorn (aoudshoo@gmail.com) 
common in experiences precipitating homelessness, during episodes of homelessness (Browne \& Bassuk, 1997; Lewinson, Thomas \& White, 2014), and serving as barriers to exiting homelessness (Watson, 2016). Pathways into homelessness differ based on gender, with more women identifying experiences of intimate partner violence (Riley et al., 2014; Whitzman, 2006). As well, on looking to exit homelessness, men and women seek differing services supports (Winetrob et al., 2017). In Canada, there is an established homeless serving system, with emergency services and supports (e.g., shelters) to mitigate homelessness, however, this approach fails both in focusing on ending homelessness (Tsemberis, 2010) and may not adequately address gendered experiences of homelessness. This is congruent with qualitative research on homelessness that points to concerns of those with lived experience that in spite of current supports, housing feels largely unattainable in the Canadian context (Morrell-Bellai, Goering \& Katherine, 2000). In a mid-sized city in Ontario, Canada, Homes 4 Women (H4W) was established as a Housing First program aimed at serving some of the most chronically homeless women in the community. The idea of Housing First programs is to help bridge the gap to housing attainment in a better supported and more permanent way. This paper presents an evaluation of this program, with a focus on the voices and experiences of the women accessing the program.

Housing First as both a philosophy and a program implementation of this philosophy has demonstrated promise when homeless people are expediently re-housed, provided the housing is: 1) affordable; 2) safe; 3) supported; and 4) permanent (Gaetz, Donaldson, Richter \& Gulliver, 2013). However, Housing First programs to date have primarily focused on the archetypal homeless individual, namely white, middle-aged men, with concurrent substance use and mental health challenges (YWCA Canada, 2013). As the experience of homelessness is gendered, so too should be the responses to homelessness and the evaluation of these responses. Therefore, evaluations are needed to understand efficacy of Housing First with particular populations, including women, youth, and Indigenous persons. Although gender should be an important consideration in all health and social services delivery, Housing First projects have generally included a proportion of women but not necessarily provided training for staff to address the unique needs of women and girls, nor conducted evaluations that consider differential, gendered experiences. This is not to say that these programs are not serving women, and having positive outcomes with some women, but rather that opportunities exist to enhance models that might better integrate gender-based promising practices. While participation in existing Housing First programs has included a proportion of women and girls, published evaluations of such programs are still quite limited.

H4W grew out of two research conferences on women's homelessness held in London in 2011 and 2014. These conferences, called All Our Sisters, brought women from coast to coast to coast together to discuss the unique needs of female-identified persons, meaning those who identify as women, in terms of becoming homeless and finding home. Participation included women with lived experience, service providers, decision-makers, and academics. It was through these conferences that a need was identified for Housing First programs for women delivered through an explicitly feminist lens, meaning programs grounded in principles of feminist theory. YMCA Canada developed a brief out of the first conference identifying concerns with the current body of evidence on Housing First (YMCA Canada, 2013) called Homes 4 Women, the name of which was then adopted for the Housing First program. The program was externally funded for a two-year time period during which it enrolled, housed, and then ultimately transitioned women to other supports. This funding supported two full-time staff members, originally structured as case managers, although their roles involved to include housing selection and housing stability work. Planned enrollment was 50 participants, or 25 per case manager. The program was delivered within an explicitly feminist framework, utilizing principles of feminist theory in policy and delivery, and the staff members were given special training and trauma and violence informed care, as well as Housing First principles and practices. 
An evaluation of the H4W program through a feminist theoretical lens serves to fill the knowledge gap on Housing First delivered with a focus on a particular population, namely women. This includes providing recommendations for further programming and research. Although Housing First is a proven model to enhance health and social outcomes for people experiencing homelessness, more research is needed as to how this model might better be adapted to particular social locations such as gender.

Housing First interventions with an evaluation component began in the United States, with the earliest and best measured model being the Pathway program out of New York, NY. As noted by Tsemberis (2015), this program evaluation proved a number of hypotheses that were current but also contested in the sector. These hypotheses included notions that people with concurrent mental health and addiction challenges can successfully live in independent housing, that permanent housing is the goal for most people experiencing homelessness, that goals for housing do not work if they are not driven by client choice, and that rent subsidies are often required to overcome financial barriers to housing. The evaluation of the model also included intervention groups exploring the role of mental health and addictions treatment in housing outcomes. The ultimate conclusion was that those who are provided housing immediately had better outcomes than those required to first meet treatment goals such as demonstrating sobriety, hence the terminology 'Housing First'. This is congruent with a philosophy of housing as a human right rather than a condition of treatment compliance.

Within the Canadian context, the At Home/Chez Soi project was the largest Housing First evaluation in the country, which included five sites across Canada. This program, again, included a focus on mental health and homelessness, although each site had a slightly different housing model varying from independent to congregate living. Across all test sites combined, the sample was $32 \%$ female-identified. As was anticipated, providing service through a Housing First modality led to improved housing outcomes and decreased impacts of mental illness (Chung et al., 2017), as well as decreased costs and service utilization, particularly for those who were the higher users of service at entry to the program (Crocker et al., 2014). Housing First in Canada: Supporting communities to end homelessness (Gaetz, Scott \& Gulliver, 2013) presents several other Canadian evaluations of Housing First programs, supporting improved quality of life, improved housing outcomes, and decreased costs. The authors do note that the majority of work focuses on single adults versus families, and we highlight that the majority of families experiencing homelessness are led by women, and although supportive housing programs for women are mentioned, only one example was specifically designed for women. More local to the program evaluated in this article, Forchuk and colleagues (2016) evaluated a Housing First program, a sample that was $33.8 \%$ femaleidentified, and noted improved health, improved housing stability, decreased emergency shelter utilization, and decreased use of emergency services as a result of the program adopting a Housing First approach. In another evaluation of Housing First focused on youth, youth participants were offered choices of housing, concurrent housing and treatment, and treatment first. Although both male-identified and female-identified youth preferred Housing First by a slim majority, $32 \%$ of male-identified youth selected treatment first while a slightly lesser $29 \%$ of female-identified youth selected treatment first (Forchuk et al., 2013). In qualitative analysis for this study it was noted that a major theme for choosing Housing First was stability for children, and this was much more likely to be identified as a concern for female-identified youth.

Housing First programs specific to women and girls are indeed being developed in the Canadian context, although they are few and far between. One of the longest standing is The Vivian out of Vancouver, developed in 2004 recognizing that women experience unique risks while homeless; they are more likely to be 'hidden', or service-disengaged, and most have complex histories of trauma (Gaetz, Scott \& Gulliver, 2013). This program has a notable nuance of using congregate living versus the more common model of individual apartments 
utilized with men, and they are also attuned to the diverse experiences of women, not only considering gender as the social location of importance, but also factors such as indigeneity and disability. Some tension is notable in the model, however, as since it is a single site the program is dependent on participants to exit before new residents can be housed. This raises a question of congruence with client choice of housing if a high turn-over is present. This model is not uncommon in situations where former transitional programs have evolved into Housing First programs, and formerly limited-term stays have been altered to be indefinite. If clients are choosing such living arrangements then these adapted programs remain congruent with the principles of Housing First, but are then size-limited by the number of units available rather than the numbers of workers available, which is the limit seen in programs that utilize market housing. Unfortunately, no evaluation of this particular program is available to date, although program statistics demonstrate positive outcomes of housing stability (Gaetz, Scott \& Gulliver, 2013). Supporting Our Sisters in Hamilton, Homeward Trust Edmonton - E4C, Street Level Women at Risk in London, and the Medicine Hat Women's Shelter Society are other examples of Housing First programs for women. Of these, only E4C has a current external evaluation, which noted the value of intensive case management, existence of complex trauma histories, the value of peer support, and the discrimination faced by women when accessing services (Potter-King \& De Jong, n.d.).

Therefore, although Housing First is a well-proven methodology generically, research evidence on Housing First for women in particular is limited. Because of this, there are few recommendations available for providing Housing First for women apart from general recommendations for promising practices in the Violence Against Women (VAW) and homeless-serving sectors. Grounded in critical feminist theory, and using a community-based participatory action research (CBPAR) methodology, the purpose of this study is to evaluate the Homes 4 Women project, including both process and outcome evaluations. The research question was: What are the impacts of the Housing First project on participants' housing stability, housing choice, and social well-being.

\section{Methods}

This evaluation was grounded in a trauma-informed, participatory, qualitative design. The methods were informed by an evaluative design used in another local Housing First program (Forchuk et al., 2016). A community-based participatory action research (Minkler \& Wallerstein, 2009) approach was facilitated by using a research advisory committee inclusive of researchers, program administrators, and direct service providers. Although findings were drafted independently by the research team, unlike traditional third-party evaluations, service providers participated in study design, addressing ethical considerations, recruitment processes, and served as key informants in interviews. To ensure trauma-informed methods, a research coordinator was employed who herself writes and educates in the area of traumainformed practice. It was ensured that this research coordinator had skills in the following areas: 1) Trauma-informed principles; 2) Responding to suicide risk; 3) Reliability in data collection; 4) Securing participant informed consent; 4) How to conduct interviews; 5) Dealing with interview termination; 6) How to handle crises/triggering; and 7) How to access a researcher on call. Congruent with CBPAR, findings are being utilized by the community to continue to inform services across the sector to enhance gender-based skills in service provision. To this end, H4W themselves hosted a design lab to address women's homelessness in their community.

The research question was addressed using qualitative and quantitative methods, consisting of semi-structured, qualitative interviews with participants ( $n=s e v e n)$, interviews with community key informants $(n=10)$, and 3 focus groups with key informants $(n=10)$. Key informants consisted of service providers, funders, and decision makers in the community working in homelessness services, and were recruited through community email lists and 
announcements at meetings. Data collection for program participants was to occur at program intake, every six months during the two-year program (the length of time for which the program had received funding), and three months post completion of the program. However, due to the long period of time for intake into the program, the final target was two interviews with each participant at varying timepoints. All of the participants were women receiving services from the H4W program, who were recruited into the program by referral from community agencies.

Qualitative data collection involved a semi-structured interview guide or focus group guide, with a focus on the impacts of gender and Housing First. Ultimately, seven of $10 \mathrm{H} 4 \mathrm{~W}$ participants consented to participation in research analysis. For clarity, these research participants will be referred to as 'participants' through the findings. Women in the H4W program were located within the local urban area, were experiencing homelessness, and were identified by referring agencies as having chronic experiences of homelessness and multiple barriers to housing stability. Of the 10 women enrolled in $\mathrm{H} 4 \mathrm{~W}$, seven identified as Caucasian, two as Indigenous, and one as Black. Six women accessed social assistance as their primary source of income, and four were accessing disability assistance. Eight of the 10 women identified as mothers, with the other two declining to answer the question. Of the eight who identified as mothers, only two had access to children at program intake, with one having full custody. Eight of the women identified as living with an addiction, and the other two declined to answer. All women identified a history of multiple traumas.

Our analysis followed Lather's (2017) criteria for validity in critical feminist research. In this context, the focus of coding and analysis is not necessarily to collapse all data into themes, but to highlight both what was common and what was inconsistent. To this end, an analysis framework was created to support coding that asked co-investigators to: 1) notice contradictions; 2) notice tensions; 3) notice hegemony; 4) notice what was learned; 5) notice what participants are telling us. As part of a program evaluation, this coding and analysis technique allows us to identify what is and is not working with the program, the diversity of experiences of the program, and to explore both the elements of Housing First in general, as well as to focus in on gendered experiences. Frequent team meetings were utilized throughout the analysis process to explore similarities and differences in what was coded. Ultimately, in keeping with Lather's prioritization of the voice of participants, we have tried to integrate quotes throughout the findings. Pseudonyms are utilized throughout in attributing quotes.

\section{Results}

\section{Barriers to Housing}

H4W staff reported that six women were successfully housed, two withdrew from the program, one returned to jail, and one was in transition at the conclusion of the study. Those six participants who were housed came from a variety of difficult situations including high use of shelter, jail, or hospital, being unsheltered, or couch surfing. Housing included both scatteredsite and congregate settings. Focused on chronically homeless women with multiple barriers to housing, participants engaged into $\mathrm{H} 4 \mathrm{~W}$ had complex histories with service access and many were disconnected from housing services at the time of intake into H4W. For some, this was in the context of being very familiar with services but choosing at this point not to use them. For others, service disengagement meant being unsheltered, or using only select services, such as accessing crash beds.

Katelyn, interviewed early after intake, spoke to how the system wasn't currently meeting her housing needs:

I was probably being shuffled from shelter to shelter. So overall it wasn't a good experience. I needed a more stable place to live. I feel that possibly getting involved 
with [H4W] I'll have something more substantial and better geared to my life and my lifestyle.

For this participant, as with others, shelters were not seen as a desired long-term housing solution. However, obtaining housing was an ongoing challenge. Deb also spoke to past challenges in obtaining housing on her own:

It's hard. It's not easy. I think that's one of the hardest parts. Unless you're extremely strong minded and strong willed, once you get put in these places that are low income it's hard to get out of that cycle.

She also spoke to broader service limitations, such as challenges around transportation:

Everywhere that I can walk, I walk. And everything that I can't, I take the bus. But everything is downtown or [mental health service] is downtown, or my doctor's appointments are at [hospital], to see my psychiatrist is, he's up at [different hospital]. So I used to rely on [support workers] to take me to those appointments because he's never on time ever so I end up waiting like 45 minutes past my appointment time so it's brutal.

Challenges with obtaining housing were connected to poverty and insufficient resources. Jess also saw the move into permanent housing as a difficult challenge:

With people that are homeless and stuff they don't have assistance like Homes 4 Women to help with rent bank and stuff.... And ODSP [Ontario Disability Support Program] only works on a month behind, so where are you going to come up with the money to pay first and last months rent and then wait for an adjustment cheque at the end of the month?" Later she stated: "So that money for basic needs was what? First and last months rent and groceries and furniture, and you can't get it. So in turn you're constantly short, right? And its difficult to try and put any money aside, especially when you're not just using but you're homeless. So sometimes you're using to stay awake, like so you don't pass out outside and get robbed, raped, murdered.

Similarly, Melody had a long history of failed tenancies prior to H4W related to hospital admissions:

For the last five years every time I go in the hospital two months, two and a half months, so I can't help it. Every time I turn around and try to get somewhere and then I'm back behind again.

She illustrated how her chronic illness made her housing situation too complex for current systems to handle, thus she resorted again and again to the shelter system. This illustrates a key opportunity for a system to maintain housing during hospitalizations.

Coming into this context, Homes 4 Women was able to engage complex and/or servicedisconnected women. The complexity of the barriers faced by participants at the time of intake into H4W illustrates a positive outcome of the program in terms of engaging women with complex needs. Jess highlighted this complexity and how women were trying to navigate the system to support their housing. At the time of her first research interview, she was in jail and her immediate concern was having been arrested while her apartment was unlocked and very messy. She wondered, would her housing still be available? Would her stuff still be there? Would she have enough money when she got out to make rent? She was considering pleading guilty just to speed up the justice process so she could check on her apartment. Complex needs also included being unsheltered, such as Angela who spoke about her preference to live unsheltered through the summer, as she considers this option provides her with a better 
quality of life than in an apartment. This participant chose to engage with Housing First through $\mathrm{H} 4 \mathrm{~W}$ in anticipation of the coming winter. Complex needs also involved service disconnection, such as Deb who had made very limited use of homeless services prior to engagement and spoke of couch surfing after leaving a violent relationship. She remarked that:

I was forced to stop my job and I had to go to Ontario Works, but the H4W stability worker set everything up for me which was great because I wouldn't have known what to do.

\section{Housing and Social Outcomes}

In terms of outcomes, most participants saw improved housing stability through their work with $\mathrm{H} 4 \mathrm{~W}$. Angela, who had been unsheltered prior to her arrest, was provided housing shortly after discharge from jail. Kim noted that the program helped her bridge the income gap to access housing and meet her vision of having her own space. Katelyn was looking forward to moving imminently from the shelter to affordable housing because, 'I've got a whole team of people that are working with me,' referring to H4W. Deb noted how the program helped her connect with the right services she needed in order to make housing a reality:

But for example, I didn't know about the stability bank until H4W or OW [Ontario Works] helped. They don't tell you they can help with a hydro bill for example. So you don't even know what they can do.

Apart from increased housing stability, improved health and improved access to children were identified as priorities of the program and the participants. Jess spoke to improved health through decreased substance use:

Since I've been working with [agency] and Homes 4 Women, like, I've used [drugs] a lot less than what I used to. Because they did give you a little bit of hope, you know.

This relationship between housing support and well-being was also noted by community key informants. A key informant stated:

I think that some women would not be alive, personally, without this program, that some women are able to access services for their addictions through this program.... Because [a housing support worker] has been there and checking in on them and asking them questions and showing them where those services are, I think that they are... [even] taking them to a public health nurse or a nurse practitioner.

In terms of improved access to her children, Deb had a very positive experience with H4W. She noted the client-driven nature of the support and that these supports have been true to her primary goal of regaining custody of her son. She notes that they haven't pushed her into housing as it has taken significant time to find housing that is truly safe for her and her son. She noted:

Like I've been involved with H4W coming on a year and I could have been housed probably within this year. But I would rather spend time away from my son right now and get in the right kind of place you know, so I can live safely with my son.

Likewise, later in the program, Jess was seeing her son after being successfully housed.

\section{Program Qualities}

In regard to what led to positive program outcomes, participants focused strongly on the nature and quality of relationships with H4W staff. This included 'doing whatever it takes', speaking 
to the adaptiveness of the program as being a key to the success women had. Jess, after being housed, stated:

So it's difficult to stay clean if you don't have a place and its difficult also to stay by yourself in your apartment. Like, I got through it but the contact everyday is important. Even if its just a phone call or something like where [H4W worker] was like, 'We're going to do this, we're going to get through this.'

One element of Housing First is 'the right support', and for participants this often included frequent contact and communication. Katelyn said:

Actually, you know what, these [H4W support workers] that I have right now. I felt very alone at first, but now everyone is in the same place and communicating with each other, instead of me against them, which I was feeling before [admission into the program], very much alone and very much isolated.

This participant repeatedly praised the program and expressed optimism for her future and exiting shelter. In a second interview, with housing imminent, she stated:

Regardless of [H4W worker] being really busy, like, she always had the time. This particular person, we just connected, and she's really good at her job. And very compassionate. And I think this one person is very special.

This contact was broadly perceived as positive, with participants noting a sense of interest in their well-being among workers. Melody noted:

[H4W worker] keeps in contact with me every day or has somebody keep in contact with me every day, to make sure I'm safe or so I don't harm myself or that I'm not being harmed.

Lastly, Deb said:

[H4W] have gone above and beyond for me (Note: client teary and demonstrating gratitude- placing right hand over her heart). I think really just getting my life back, because losing control of your life is really hard.

\section{Program Tensions}

Despite being able to achieve positive outcomes related to moving participants from basic stability and access to services to permanent housing of their choice, there was noted tension around this idea of choice. In many ways, participants felt required to follow staff recommendations even though staff clearly stated that participant choice was always the priority. At the same time, staff felt pressured to achieve permanent housing outcomes for participants in the context of a system that has resource limitations. Participants highlighted some of these pressures, with Helen saying:

[H4W] supplied me with a real heavy tv/dvd player that was appreciated because I had no cable, and a really, really heavy queen size mat/box, [that] practically filled up the entire room. I had no say in this, and if was given the chance, would have gone with something a lot smaller... Month later, we view another [apartment], was supposed to view the bachelor but because of a missed message that I left and was not forwarded, it was given to another [participant]. So I took the one bedroom, it was more expensive, but it was available.... Homes 4 Women put together a support team, four women. What was I going to say, "No"? I needed housing, I did not sign up for therapy. 
Jess also highlights this tension well. She was successfully housed and very grateful for this, but then did not find she received enough in-home support, which was largely related to a change in her primary worker that she did not anticipate:

And Homes 4 Women did have a good plan for me when I got out [of jail]. They got me bail to my new address. They got me an apartment without me even seeing it. Everything was lined up perfect, its just the support wasn't there for me when I got out.

Angela liked her apartment, but at the same time contextualized her comments by saying, 'I'm not too picky- it's fine. It's an apartment.' Katelyn was thoughtful about existing within a system that has limited resources. She acknowledged that it's easy to have a vision for housing that does not meet the reality of this system, noting that she has, 'Beer pockets but champagne taste.' Overall, she felt satisfied with the housing she was going to move into even though it did not quite meet her ideal vision. That said, conversely Deb, who was one of the most quickly and permanently housed participants, noted that she was able to change primary workers at least three times until she was with someone she preferred. However, she also notes that her current housing is not sustainable financially unless she regains full custody of her son, putting her in a precarious position.

Helen had a generally negative experience with $\mathrm{H} 4 \mathrm{~W}$, and ultimately quit the program. She states:

[H4W] came with me to the rent bank, as advisers; but I was pretty much told to be quiet and let them do the talking. So, I sat back and did just that, handed them the controls... They bought and supplied me with things, not all that great mind you, but when you have nothing, anything is better. I was always appreciative and said so.

There is a tension here between being grateful for receiving support, while in some way losing one's autonomy or decision-making capacity. Angela speaks to a feeling of lost independence:

It's hard to set up things yourself when there's other people helping you. It's hard to live in an apartment when there's other people paying for it. I've been an independent person my whole life you know but maybe I just need some help right now to get off the streets.

Participants noted weighing the consequences of asserting their autonomy, with Kim sharing that she took the first place offered even though it wasn't in a neighbourhood she knew as she did not want 'to appear picky'. She hadn't disclosed this to the H4W worker. That's not to say that participants want to drive all decisions, as Deb talks about not being involved in her housing selection too much, but at the same time states that this was fully her choice and she was happy with the process:

I just kind of put it in Homes 4 Women's hands and let them pick out the places that the landlords aren't going to give you such a hard time.

On the other hand, Deb also noted that supports promised from a collaborating agency were ultimately withdrawn. H4W staff were aware of the challenge of working in a system where power is unequally shared, stating:

One thing that keeps coming up for me is the relationship that we have with the people that we serve. There's this just "us and them" even though we like to think that doesn't exist. 


\section{Noted Future Directions}

In terms of opportunities for program improvement, participants noted some of the resources of the program did not always match promised supports. Angela noted that her first apartment was unfurnished when she moved in and she grew bored; this was remedied at a second tenancy. She also noted that an apartment wasn't immediately available after discharge from jail as had been hoped. Melody spoke of a failed tenancy that did not match what was promised and did not meet her needs:

When I moved into [name of street] I really wasn't comfortable right from the get-go. It was a bachelor and I was told it was going to be at least a one bedroom and I knew I wanted my son with me because he had taken me into the [name of motel]. So, I wanted somebody there with me and he wanted to be there with me because he knew I was sick and he didn't have a place to go because he had spent all his money too.

Jess, after being successfully housed, said:

But I mean [H4W] will tell you they were limited in what they were helping me with I guess. I think it would be best if someone answered the phone when you call. A lot of people don't have phones. I could never get ahold of [one of her two H4W workers].

Ultimately, although the initial conceptualization of H4W was that no woman would be discharged, ultimately some were. Helen struggled most with $\mathrm{H} 4 \mathrm{~W}$, and shortly after asking her housing stability workers not to contact her anymore and withdrawing from the program, she had a conflict with the landlord and was ultimately evicted. Jess withdrew as she moved out of town.

It is worth noting the incredible resiliency demonstrated by the participants. For example, Melody noted that after years of being unsheltered or in emergency shelter she had been motivated by reconnecting with her teenage and adult children to find housing and stability. She shared:

I want to be become a big truck driver like my dad and stuff like that, so I can have enough to save for a home and do my businesses and that. I used to clean, I worked three jobs you know my whole life. Yah, I was raising the kids basically by myself too.

Referring to her kids, and having a partner leave her, she stated, 'I tried to keep them by my side at all times so they didn't get hurt like I was.' She shared a horrific history of multiple violent partners, sexual traumas, abandonments, and ultimately guilt that her children were apprehended and were experiencing the same traumatic and substance-involved lives that she had. At the end of these stories she stated, 'And I can't give up trusting [people].'

Jess shared a history of psychosis that led to hospitalization and conflict with the law. This was subsequent to experiencing physical abuse from a partner and trying to keep a challenging job while also supporting her child. She is proud that she is seeing her son now, managed her money well after jail, is following her plan for abstinence from substances, and participating in rehab.

\section{Housing First Fidelity}

$\mathrm{H} 4 \mathrm{~W}$ was designed as a Housing First program geared particularly towards women, and was successful in permanently housing a small number chronically homeless women. Housing First is grounded in a number of principles, and adherence to these principles is one measure of program evaluation. For this evaluation, the Homelessness Partnering Strategy (HPS) criteria of fidelity were utilized, and fidelity was assessed as follows: 
Table 1. Housing First Fidelity

\begin{tabular}{|c|l|}
\hline Core Principles & $\begin{array}{l}\text { Partially Achieved - With staff working } \\
\text { across case management, housing } \\
\text { selection, and housing support, or } \\
\text { depending on other Housing First programs, } \\
\text { housing was not always rapidly available. }\end{array}$ \\
\hline 2. Housing choice & $\begin{array}{l}\text { Partially Achieved - This was achieved in } \\
\text { part because participants were anticipating } \\
\text { the limitations of services and resources and } \\
\text { not resisting offers of housing, or were self- } \\
\text { limiting what they asked for. }\end{array}$ \\
\hline 3. Separating housing provision from \\
other services & $\begin{array}{l}\text { Not Achieved - As noted below, there was } \\
\text { blurring in staff roles as they covered all } \\
\text { aspects of Housing First. Significant staff } \\
\text { time went into activities better covered by } \\
\text { outreach for example. }\end{array}$ \\
\hline
\end{tabular}

4. Integrated housing (security of Achieved - Housing permanency was tenure) initially achieved through $\mathrm{H} 4 \mathrm{~W}$, then sustained through transitioning participants to other programs near the end of funding. This was a noted risk as the program was time-limited at the outset.

5. Tenancy rights and responsibilities (legal title to unit)

6. Reasonable (per cent of income) cost for housing

7. Housing support

Service Philosophy

1. Service choice
Achieved

Partially Achieved - It is noted the importance of rent subsidy in achieving this goal. Some participants still spent a majority of their income on rent.

Achieved

Partially Achieved - Participants disclosed to the evaluators times where they felt choices were limited, although did not disclose this to staff as they were grateful for the support. There was a lack of policy clarity around 'assertive engagement' and when to discharge a participant, but discharges made were following the participants' choices to withdraw from the program.

2. Participant-driven program and Partially Achieved-As per comments under services 'housing choice', the philosophy was indeed to be participant-driven. Again, however, participants at times weighed the costs and benefits and ultimately chose at times not to exercise their autonomy.

3. Contact with participants

Achieved - Most participants noted the consistency and frequency of team support, although a few mentioned difficulty in contacting workers by phone at times.

4. Continuous services completion at the end of the initial funding cycle. As above, permanency of housing 


\begin{tabular}{|c|l|}
\hline \multicolumn{1}{|c|}{} & $\begin{array}{l}\text { was achieved through transition of } \\
\text { participant to other programs, but this did } \\
\text { involve a shift in housing supports. For } \\
\text { some, this also reduced access to housing } \\
\text { allowances/funding, putting long-term } \\
\text { housing in jeopardy. }\end{array}$ \\
\hline 5. Directly offers or brokers services & $\begin{array}{l}\text { Achieved - Housing selection and housing } \\
\text { stability were either provided directly by the } \\
\text { program or through direct transfers to other } \\
\text { Housing First programs. }\end{array}$ \\
\hline 6. Selection of vulnerable populations & $\begin{array}{l}\text { Achieved - The use of a vulnerability } \\
\text { assessment tool facilitated selection. }\end{array}$ \\
\hline Team Structure/Human Resources & $\begin{array}{l}\text { Achieved - It is noted that to achieve this } \\
\text { involved intake of participants significantly } \\
\text { lower than initially anticipated. }\end{array}$ \\
\hline \multicolumn{2}{|l}{ 1. Low participant/staff ratio }
\end{tabular}

Overall, the program achieved good fidelity to the principles of Housing First with a number of noted opportunities for improvement. Achievement of full fidelity could be achieved through the following recommendations: 1) More development time to understand policy and staff roles; 2) More time to understand interaction, integration, and collaboration with other service partners, including formal partnership development; 3) Delaying intake until these developmental components are completed; and 4) Increased resources to increase the staff compliment across a variety of Housing First roles.

\section{Discussion}

$\mathrm{H} 4 \mathrm{~W}$ was able to provide valuable support for a period of time with some of the women in their community who were experiencing homelessness most chronically and with complex trauma histories. Women for the most part were accessing emergency services versus stable housing supports, entering the program from couch-surfing, jail, or being unsheltered. Trajectories prior to engagement in the program were exceptionally poor and service utilization tended towards the most costly and least supportive modalities, such as provincial detention.

The need for both increased and better integrated community mental health supports has been repeatedly identified as a priority issue in the region of this program (Whaley and Co., 2011; Whaley and Co., 2014). It is noted that Housing First programs with intensive case management, such as $\mathrm{H} 4 \mathrm{~W}$, primarily support the population of people living in the community with significant addiction and mental health challenges (Goering et al., 2011). Therefore, there is clear intersection here between the homeless-serving system and the community mental health system, with Housing First in a way filling a portion of the gap in mental health supports noted above. Where the women supported through $\mathrm{H} 4 \mathrm{~W}$ would benefit from long-term addiction and mental health support, in addition to permanent housing, the current mental health services in their community seemed to be beyond capacity or not geared towards women with complex challenges. The stressed nature of community mental health supports is congruent with other Canadian research into system gaps for women living in the community with mental health challenges (Drabble \& Mclnnes, 2017). Therefore, the program filled an important need in the community and concurrently with another program for street-involved sex workers was providing women-specific services to those with complex trauma histories. It was clear that this mode of programming is necessary if the needs of women experiencing chronic homelessness are going to be met. 
The overlap between Housing First and community mental health supports raises a broader question of system design and long-term plans to support vulnerable people in housingfocused modalities. The homeless-serving sector has traditionally focused primarily on absolute homelessness or those in emergency shelter. Indeed, this is where the bulk of federal, provincial, and municipal funding was focused prior to the advent of Housing First (Tsemberis \& Stergiopoulos, 2013). A shift in focus and finances to focus on prevention and rapid rehousing, through programs such as Housing First for women and girls, is a significant and evidence-based policy reform. However, if implemented without integration with existing community mental health supports, there are simply insufficient resources within the homeless-serving sector to indefinitely support every person who is precariously housed or who has had some experience of homelessness. Even the current focus on high acuity, chronic homelessness, and the thoughtful community application of the Vulnerability IndexService Prioritization Decision Assistance Prescreen Tool (VI-SPDAT) yields more potential participants than system capacity.

Where programs of the homeless-serving sector reach beyond the streets and emergency shelters, there appears to be overlap with the community mental health support system. This overlap needs to be addressed thoughtfully in an inter-sectoral manner so that those with the most resources and with the appropriate skillsets are providing the care. H4W benefited from being within a community mental health organization where there was some ability to thoughtfully move participants to the right type of support, but even within the agency there was some tension with this, and within the broader community, there is limited planning as to how clients would move intentionally through different systems of support. While the expansion of programs that provide Housing First for women is an obvious next step based on this evaluation, this should be done hand-in-hand with a comprehensive community plan for community-based long-term mental health supports (Watson, Fossey \& Harvey, 2018). The healthcare sector and the homeless-serving sector need to work more collaboratively in planning for long-term support of vulnerable persons.

This need for greater consideration of how Housing First programs integrate with other community support services highlights some of what can be learned for improving future iterations of Housing First programs for women. As with many calls for funding, a vision exists and there is congruence between this vision and the funding call. Therefore, an application is constructed but often with limited time and consultation. The unique needs of women experiencing homelessness to be rehoused, and the need to design Housing First programs specifically for women, was an evidence-based and timely focus for those who developed the program proposal. At the same time, driven by the urgency of the immediate needs of women, oftentimes due to street-involvement, there was limited community dialogue and preconsultation as to how this program would integrate with the broader homeless-serving sector. During the evaluation, one key informant in the community highlighted, 'We've had to work pretty hard at dealing with Homes 4 Women because it came sideways.' Therefore, upon successful funding and launch of the program, there was initially limited familiarity with the program from other services who had past or current interactions with the women subsequently engaged into $\mathrm{H} 4 \mathrm{~W}$. The program framework, policy development, and staff recruitment were iterative processes, which meant that the program could not be easily explained at the outset where design was still in progress. There was both confusion among community partners, and where relationship tensions pre-existed, an ease to write off the program as poorly conceived. Some saw the termination of the program as evidence that it was developed in the first place with limited community-wide collaboration, although it included intense collaboration among the lead partners, and consistent collaboration with community table members.

Although Housing First works for women, as demonstrated in this evaluation, it should also be noted that Housing First when poorly delivered or when delivered without consideration of gendered factors can put women at risk or push women out of services. For example, workers 
lacking skills in safety planning might facilitate a move for a woman that puts her at risk of reconnection with her abusive partner. Or, workers may alienate women from Housing First programs by providing services or supports that are incongruent with their goals of regaining visitation or custody of their children. Inconsistent communication and service provision can also alienate women from service. These real-world examples were provided by study participants. Other risks include insufficient assessment of safety in relation to landlords, with stories of female-identified Housing First participants falling victim to predatory landlords.

Lastly, the issue of the trauma of grief and loss due to child apprehension came up again and again through the interviews. It is noted that across Canada few services currently exist to address this particular grief and loss, and access to psychological supports in general is very difficult with these supports not being covered under provincial health insurance programs. Addressing these root traumas needs to be an immediate priority for women experiencing homelessness if we are to assist in stopping the cycle of episodic and chronic homelessness. Congruent with a CBPAR methodology, as this concern was identified through the study a community organization local to the study started such a service, before the study was even concluded. This demonstrates potential benefits of evaluations conducted in partnership with the community.

This study faced limitations of a limited sample due to limited program intake. As well, the concerns of the women related to services might be geographically or contextually impacted. Lastly, as the program ended on completion of the funding window, there was no opportunity to track program participants over a truly longitudinal time period. While this study evaluated gendered services delivered in an urban environment, future research should integrate other contextual factors such as women in rural and remote communities. With intimate partner violence being a common factor in pathways to homelessness for women, and the experience of intimate partner violence in rural and remote communities being different (Shannon et al., 2006), assumptions should not be made about the applicability of gendered Housing First programs in all regions. This evaluation also included diversity around ethnicity and culture, yet these concepts did not come through strongly in the words of the women or the assessment of housing outcomes. Future work should explore more explicitly cultural experiences of women's homelessness, with clear consideration of issues such as race and indigeneity. While our analysis shifts from considering homelessness in a de-gendered manner to making gender central, we should not fall into a similar reductionist trap of considering that the experiences of all women and girls are equal.

To conclude, while Housing First is a promising philosophy which has been adapted into a number of successful programs, the next steps in using this model to solve homelessness include considering the unique needs of specific populations and evolving existing promising practices within these populations to the Housing First context. 


\section{References}

Berman, H., Gorlick, C., Csiernik, R., S.L. Ray, S.L., Forchuk, C. Jensen, E. \& Al-Zoubi, F. (2011). The Changing Face of Diversity in the Context of Homelessness. In Homelessness, housing and mental health: Finding truths - Creating change edited by C. Forchuk, R. Csiernik, and E. Jensen, 205-228. Toronto: Canadian Scholars' Press.

Browne, A. \& Bassuk, S.S. (1997). Intimate Violence in the Lives of Homeless and Poor Housed Women: Prevalence and Patterns in an Ethnically Diverse Sample. American Journal of Orthopsychiatry, 67, 261-278. doi:10.1037/h008023.

Chung, T. E., Gozdzik, A., Palma Lazgare, L. I., To, M. J., Aubry, T., Frankish, J., \& Stergiopoulos, V. (2018). Housing First for older homeless adults with mental illness: a subgroup analysis of the At Home/Chez Soi randomized controlled trial. International Journal of Geriatric Psychiatry, 33(1), 85-95.

Crocker, A.G., Nicholls, T.L. Roy, L., Martin, M.S. Lemieux, A.J., Petersen, K. \& Pritchard, M. (2014). Criminal Justice Involvement and Victimization Outcomes: Results from the At Home/Chez Soi Project. Ottawa, ON, Canada: Mental Health Commission of Canada.

Drabble, J. \& Mclnnes, S. (2017). Finding Her Home: A Gender-Based Analysis of the Homelessness Crisis in Winnipeg. Available at https://www.policyalternatives.ca/publications/reports/finding-her-home (accessed June 13, 2018).

Forchuk, C., Richardson, J., Laverty, K., Bryant, M., Rudnick, A., Csiernik, R., Edwards, B., Fisman, S., Mitchell, B., Connoy, M., Dolson, M. \& Kelley, C. (2013). Service Preferences ofHomeless Youth with Mental Illness: Housing First, Treatment First, or both Together. In Youth Homelessness in Canada: Implications for Policy and Practice edited by S. Gaetz, S. O'Grady, K. Buccieri, J. Karabanow, and A. Marsolais. Toronto: Canadian Observatory on Homelessness.

Forchuk, C., Richardson, J., Martin, G., Warner, L., Oudshoorn, A., Taan, W. \& Csiernik, R. (2016). An Evaluation of the London Community Addiction Response Strategy (London CAReS): Facilitating Service Integration Through Collaborative Best Practices. In Exploring Effective Systems Responses to Homelessness edited by N. Nichols, and C. Doberstein. Toronto: The Homeless Hub Press.

Gaetz, S., Donaldson, J., Richter, T. \& Gulliver, T. (2013). The State of Homelessness in Canada 2013. Available at http://homelesshub.ca/sites/default/files/SOHC2103.pdf (accessed Mar 14, 2018).

Gaetz, S., Scott, F. \& Gulliver, T. (2013). Housing First in Canada: Supporting Communities to End Homelessness. Toronto: Canadian Homelessness Research Network Press. Goering, P. N., Streiner, D. L., Adair, C., Aubry, T., Barker, J., Distasio, J. \& Zabkiewicz, D. M. (2011). The At Home/Chez Soi trial protocol: a pragmatic, multi-site, randomised controlled trial of a Housing First intervention for homeless individuals with mental illness in five Canadian cities. BMJ open, 1(2), e000323.

Lather, P. (2017). (Post)Critical Methodologies: The Science Possible After the Critiques: The Selected Works of Patti Lather. New York: Routledge.

Lewinson, T., Thomas, M. L., \& White, S. (2014). Traumatic transitions: Homeless women's narratives of abuse, loss, and fear. Affilia: Journal Of Women \& Social Work, 29(2), 192-205.

Minkler, M. \& Wallerstein, N. (2009). Introduction to CBPR: New Issues and Emphases. In Community-Based Participatory Research: From Process to Outcomes edited by M. Minkler and N. Wallerstein. San Francisco, CA: John Wiley \& Sons.

Morrell-Bellai, T., Goering, P., \& Katherine, B. (2000). Becoming and remaining homeless: A qualitative investigation. Issues in mental health nursing, 21(6), 581-604.

Potter-King, G. \& De Jong, I. (n.d.) Intensive Case Management Considerations to Improve 
Housing Stability Amongst Women Involved in High-Risk and/or Exploitative Situations. Final Report. Available at http://www.homewardtrust.ca/images/resources/2013-02-06-1459OrgCode_FINAL_2013\%2001\%2030.pdf (accessed Dec 14, 2017).

Riley, E. D., Cohen, J., Knight, K. R., Decker, A., Marson, K., \& Shumway, M. (2014). Recent violence in a community-based sample of homeless and unstably housed women with high levels of psychiatric comorbidity. American journal of public health, 104(9), 16571663.

Shannon, L., Logan, T. K., Cole, J., \& Medley, K. (2006). Help-seeking and coping strategies for intimate partner violence in rural and urban women. Violence and victims, 21(2), 167.

Tsemberis, S. (2010). Housing First: Ending Homelessness, Promoting Recovery and Reducing Costs. In How to House the Homeless edited by I. Ellen and B. O'Flaherty. Juneau.org.

Tsemberis, S. (2015). Housing First: The Pathways Model to End Homelessness for People with Mental Health and Substance Use Disorders. Hazelden Publishing: Center City, MN.

Tsemberis, S. \& Stergiopoulos, V. (2013). How the federal government plans to end homelessness. The Star, Commentary, April 30. Available at https://www.thestar.com/opinion/commentary/2013/04/30/how_the_federal_governm ent_plans_to_end_homelessness.html (accessed Aug 14, 2018).

Watson, J. (2016). Gender-based violence and young homeless women: femininity, embodiment and vicarious physical capital. The Sociological Review, 64(2), 256-273.

Watson, J., Fossey, E., \& Harvey, C. (2018). A home but how to connect with others? A qualitative meta-synthesis of experiences of people with mental illness living in supported housing. Health \& Social Care in the Community. DOI:10.1111/hsc.12615

Whaley \& Co. (2011). The Time is Now: A Plan for Enhancing Community-based Mental Health and Addiction Services in the South West LHIN. South West Local Health Integration Network.

Whaley \& Co. (2014). Community Capacity Refresh: A Progress Report on the Implementation of the South West LHIN's 2011 Community Capacity Report for Mental Health and Addiction Services. South West Local Health Integration Network.

Whitzman, C. (2006). At the Intersection of Invisibilities: Canadian Women, Homelessness and Health Outside the 'Big City'. Gender, Place \& Culture, 13(4), 383-399.

Winetrobe, H., Wenzel, S., Rhoades, H., Henwood, B., Rice, E., \& Harris, T. (2017). Differences in health and social support between homeless men and women entering permanent supportive housing. Women's Health Issues, 27(3), 286-293.

YWCA Canada (2013). Housing First, Women Second? A Brief for the Homes for Women Campaign. Available at http://ywcacanada.ca/data/documents/00000382.pdf (accessed June 26, 2017).

\section{Biographical Notes}

Abe Oudshoorn is an Assistant Professor in the Arthur Labatt Family School of Nursing at Western University and a member of the Centre for Research on Health Equity and Social Inclusion. Having worked as a nurse with people experiencing homelessness, Dr. Oudshoorn's research focuses on health, homelessness, gender, trauma, housing policy, mental health, and poverty. Outside of the University, Dr. Oudshoorn is on the Steering Committee of the London Homeless Coalition. 
Cheryl Forchuk is a Professor in the Arthur Labatt Family School of Nursing at Western University, with a cross appointment to the Department of Psychiatry, Schulich School of Medicine \& Dentistry, and the Beryl and Richard Ivey Research Chair in Aging, Mental Health, Rehabilitation and Recovery at the Lawson Health Research Institute where she is the Group Leader, Mental Health/Health Outcomes Research. Dr. Forchuk was appointed to the Order of Ontario in 2017.

Jodi Hall is a Professor in the School of Nursing, Fanshawe College, and an Adjunct Assistant Professor in the School of Nursing at Western University. She is the co-counder and clinical coordinator at Sharing Spaces London, offering counselling support to individuals and families through the reproductive journey.

Tracy Smith-Carrier is an Assistant Professor in the School of Social Work, King's University College at Western University. Her research explores how social welfare programs and services can be expanded to support marginalized populations, including research on social assistance trends in Ontario and potential intergenerational linkages in social assistance receipt.

Amy Van Berkum is a professional practice consultant with St. Joseph's Health Care London. She has coordinated a number of research projects looking at the unique needs of subpopulations of those experiencing homelessness, including women and girls. 